\title{
A Survey of the quality of nursing care in several health districts in South Africa.
}

\author{
Leana R Uys* and Joanne R Naidoo
}

\author{
Address: School of Nursing, University of Natal, Durban, South Africa \\ Email: Leana R Uys* - uys@ukzn.ac.za; Joanne R Naidoo - kistenjr@ukzn.ac.za \\ * Corresponding author
}

Published: 03 February 2004

BMC Nursing 2004, 3:1
Received: 27 August 2003

Accepted: 03 February 2004

This article is available from: http://www.biomedcentral.com/I472-6955/3/I

(C) 2004 Uys and Naidoo; licensee BioMed Central Ltd. This is an Open Access article: verbatim copying and redistribution of this article are permitted in all media for any purpose, provided this notice is preserved along with the article's original URL.

\begin{abstract}
Background: South Africa is currently focusing strongly on human resource development. The purpose of this study was to describe and compare the quality of nursing service and care in three health districts in the KwaZulu Natal Province. To identify deficiencies which could be addressed by education and training, it might be useful to measure the quality of care given by nurses.

Methods: From March to August 2002 a survey was done in six hospitals and six clinics in three health districts of the KwaZulu-Natal province of South Africa. Five different aspects of care was evaluated; hand-over from one nursing shift to another, implementation of universal precautions, patient satisfaction, nursing records, management of chronic illnesses. All these aspects were evaluated using checklists based on record reviews or direct observation, except for patient satisfaction, which was evaluated by questionnaires.

Results: The average scores on the different aspects varied from II\% (for nursing records) to $73 \%$ (for management of chronic diseases). Specific problems became evident. In one district three out of four hand-overs between shifts of nurses scored less than $50 \%$. In all three districts the use of protective gear scored low (43\%). While the average score for management of chronic illnesses were high at $73 \%$, the blood pressures of only $23 \%$ was within the target range, and the blood sugar of only $38 \%$ of patients were controlled. Patient satisfaction averaged $72 \%$ across the three districts.
\end{abstract}

Conclusion: The quality of care measurements identified specific training needs, but other management strategies are probably also indicated.

\section{Background}

South Africa is currently focusing much attention on developing the human resources of the country. A Skills Development Act passed in 2000 [1] makes it compulsory for all employers to develop their workers, and the Skills Development Levies Act [2] makes earmarked funding available for the development of the work force. The expected outcomes of such training are better service delivery or, in the case of the health services, better quality of health care. It seems logical that the evaluation of quality of care would be a useful way of directing such skills development strategies. Based on Booysens and Minnaars [3] description of quality control in health services, quality of care can thus be defined as a dynamic quality indicating that the right things are being done right, improving the outcomes for patients, their families and their communities. The criteria used to assess quality could address structure, process or outcome. It is also 
important to know whether there is a difference between districts, since that would indicate whether development programmes should be developed for individual districts, or for the province as a whole.

Another reason for measuring quality is that the quality of care is one of the most important goals of a health service, and should be regularly evaluated. The process of evaluating quality has a number of problems. It is often an internal process, with results not shared with other health professionals, consumers or researchers. In many cases institutions or services set their own standards and develop criteria [4]. This makes the development of norms difficult [5], and may allow a service to be complacent about low levels of service. These practices also mitigate against two basic tenets of quality improvement identified by Morris [6]. He said firstly that quality improvement should be oriented to meeting the needs and the expectations of the patient and community (not of service providers only), and secondly that it should allow analysis of the data to describe wider service delivery.

Beattie, Rispel and Cabral [7] looked at the quality of Primary Health Care services by using a number of measurements, such as a check list to evaluate physical facilities, questionnaires to assess the attitude of clients and personnel, measured waiting time of clients as one aspect of quality, a record review of clients with diabetes and STD's to assess compliance with policy on the management of these conditions, and measured chronic disease attendance. This study showed that no single measurement of quality of any comprehensive service is possible. EdwardsMiller also looked at quality of care in South African health services, but focused mainly on input variables, such as water, electricity, and availability of drugs or services [8]. However, it was not possible to identify the contribution of nursing to most of her indicators.

The purpose of this study was to describe and compare the quality of nursing service and care in three health districts in the KwaZulu Natal Province. This study was the first phase in a larger study that aimed at evaluating the effectiveness of different training and management strategies.

\section{Methods}

A survey was conducted in all levels of health services in three health districts, which was conveniently chosen because of the ongoing training and management interventions. In this study five indicators of quality of care were selected for a number of reasons:

1. In Primary Health Care (PHC) clinics, a major part of the role of the nurse is to manage chronic conditions. Two conditions were therefore chosen to evaluate the clinical role of the PHC nurse. According to the 2003 burden of disease estimates for South Africa [9], stroke is the $8^{\text {th }}$ ranking disease, and diabetes mellitus the $12^{\text {th }}$ ranked. It is the two conditions out of the top 20 ranked causes of premature mortality that are seen at all PHC clinics.

2. In hospitals, the quality of the work of the team of nurses is heavily dependent on their communication with each other. Two indicators of this communication were selected (i.e. handover and nursing records) to evaluate the clinical role of the hospital nurses.

3. We wanted one clinical indicator that could be used across setting. Since this is an area with a high prevalence rate of HIV/AIDS, in a South African Department of Health study, it was noted that the KwaZulu Natal province the estimated prevalence rate for 2002 was $36.5 \%$ among antenatal clinic attendees and within the age group of 25 to 29 years, the 2002 prevalence percentage was $34.5 \%[10]$, thus the universal precautions indicator was selected.

4. Patient satisfaction was also selected as an outcome measure that could be evaluated across settings.

\section{Settings}

All three districts represented a relatively typical rural district in terms of their population and service spread. Table 1 highlights a brief description of the three districts.

Table I: Description of government health services in the three Districts

\begin{tabular}{lccc}
\hline & Uthukela & Ugu & Amajuba \\
\hline Regional Hospital & 1 & 1 & 1 \\
District Hospital & 2 & 5 & 6 \\
Community Health Centre & 3 & 0 & 0 \\
Fixed Provincial PHC clinics & 25 & 34 & - \\
Fixed Local Authority PHC clinics & 9 & 14 & - \\
Mobile Clinics & 18 & 7 & - \\
\hline
\end{tabular}

- = Missing data 


\section{Data collection}

Three clinics were randomly selected in each district, and a clinic close to each of these clinics was then also selected conveniently for record reviews for management of specific conditions, and for observation of universal precautions. Patient satisfaction was also assessed in the same selected clinics. All patients at the clinic with the targeted condition were asked to allow for a review of their patient - carried cards, until the desired sample size was reached. Patient-carried cards are patient records on which health service providers document diagnoses, treatment and monitoring data. The patient keeps the card in order to have this information accessible should they require services from different health care settings. If the patient does not bring the card, a new card is usually issued.

The one regional hospital in the district was purposively selected, and one district hospital was randomly selected in each district. This number is recommended in the literature [11]. In each hospital the records of 15 randomly selected patients were selected in a medical, a surgical and a gynaecological unit, and the quality of nursing records evaluated. One hand-over was assessed with a checklist in each sampled unit, and adherence to universal precautions was observed in the same units. All patients in the hospital were given patient satisfaction questionnaires. Data were collected by fieldworkers who were all registered nurses and who had been trained to use the instruments.

\section{Instruments}

1. The hand-over procedure of one team of nurses was evaluated using a ten-item checklist. Three items are given to illustrate the contents, the interpersonal skills; "Nurse in charge of the shift waits for sister in charge of next shift to arrive on duty", the ethical aspect; " Scheduled Drug cupboard keys handed over to sister in charge of next shift by charge sister going off duty" and the clinical aspect; " Handover included physical as well as psychosocial aspects of care". The internal consistency of this instrument was measured using the Cronbach Alpha co-efficient; the alpha coefficient of this scale was 0.72 .

2. Universal precautions were evaluated with a 15-item checklist. The first five items of the instrument focused on aspects relating to the "sharps container" (e.g. Checking if the sharps container is assembled correctly and not overfilled), six items dealt with aspects relating to "protective gear" (e.g. Gloves worn with invasive procedures), and three items focused on "the procedure of handling and discarding body fluids". As this instrument was not used before, the internal consistency of the tool measured was measured using the Cronbach Alpha Coefficient. The results yielded showed an internal consistency of 0.60 .
3. Patient satisfaction was measured with a questionnaire. Two types of questionnaires were administered to assess the level of patient satisfaction. In cases were patients were illiterate, a questionnaire with three faces with different expressions describing, Satisfied, Neither satisfied nor dissatisfied and Dissatisfied was used. This is a one-item scale, and patients marked the appropriate face themselves. A 28-item questionnaire was used for individuals that were literate. The questionnaire was in English and Zulu. The internal consistency of the long questionnaire was measured using the Cronbach Coefficient and it was 0.92 .

4. The Nursing Records Standards Sheet (NRSS) was used to evaluate the quality of the nurse's documentation. This instrument was developed and tested in South Africa and mostly consists of criterion referenced items. Construct validity was based on the fact that the instrument showed a significant difference in quality of documentation depending on staffing levels and bed occupancy, which has been to support a claim of construct validity. Interrater reliability has been found between 0.797 and 1.000 [9]. The items of this instrument covered the following components of an individual patient's record; legality, administration, assessment, process, discharge and effectiveness. The quality of the records was assessed, based on 82 items, and the final score is expressed as a percentage of agreement between what is expected (criterion) and what was documented (performance).

5. Management of Chronic Conditions (Diabetes and Hypertension) was assessed with a record audit tool. This tool aimed to assess the quality of the management of individuals with a chronic condition, specifically hypertension and diabetes. This is part of the role of PHC nurses in clinics in South Africa to monitor symptoms and adjust medication according to the guidelines in the Essential Drug List. Four areas were assessed; the number of visits to the clinic, the number of times the clients blood pressure or blood sugar was observed, the number of times the observation was with the normal limits (i.e. blood pressure below 90/130 $\mathrm{mmHg}$ and the blood sugar below $10.0 \mathrm{mmol} / \mathrm{L}$ ) and the medication that was prescribed by the nursing staff and whether it complied with the Essential Drug List (EDL). This information was sought from the patient-held cards.

None of the instruments addressed the demographics of the patients.

Permission for the research was obtained from the appropriate health service managers, after ethical clearance by the University's Ethics Committee. Each of the sampled clinics and hospital units were approach by letter, explaining the research to them and asking them to participate. If 
Table 2: Hand-over scores of the three districts

\begin{tabular}{lccc}
\hline SCORES & Ugu $(n=4)$ & Uthukela $(n=4)$ & Amajuba $(n=2)$ \\
\hline $0-5$ & 1 & 3 & 0 \\
6-10 & 3 & 1 & 2 \\
AVERAGE & 6.2 & 4 & 8.5 \\
\hline
\end{tabular}

they agree by returning an agreement form, an appointment was made with the nurse in charge for the observations and record reviews. The focus of the record reviews and observation were confidential, although nurses knew that the quality of certain aspects of care was being measured. This ensured that performance is not unduly influenced by the measurement.

\section{Analyses}

Internal consistency of all the instruments was calculated, using the Cronbach-Alpha Coefficient, and then frequencies, means and standard deviations were calculated. The significance of differences between districts was calculated using the Pearson Chi-Square test.

\section{Results \\ Handover}

The nurse's hand-over was observed in ten different units in the three districts. The average score obtained was 5.8 out of a possible 10, and a standard deviation of 2.6. The observations from each district was Ugu $=4(40 \%)$, Uthukela $=4(40 \%)$ and Amajuba $=2(20 \%)$. Even though $60 \%$ of the observations obtained a positive score, which was between $6-10$, it was observed in $50 \%$ of the cases (i.e. 5), that the nurse's verbal report did not include aspects of psychosocial care. Furthermore, one district (Uthukela) fared particularly poorly on the total score. A significance test performed on the data using the Pearson Chi-Square test did not show a significant difference between the three districts, ((CI 4.18-7.42), $\mathrm{r}=3.750, \mathrm{df}=$ $2, \mathrm{p}=0.153)$. Table 2 highlights the scores obtained from the different districts.

The first seven items of the instrument focused on the technique/procedure of the hand-over (e.g. roll call done by nurse in charge), the last three items deals with the handling of scheduled drugs and the procedure followed for an incident (e.g. Drug registers checked for correctness by both registered nurses). The average score for the first seven items in all three districts was 4.4 (63\%), whereas the average score for the last three items was $1.3(43 \%)$. Thus in all three districts, there is a poor response to issues relating to the correct procedures to be followed with regards to the management of the drug registers and with report writing for negative incidents that may occur.

\section{Universal Precautions}

The average scores obtained from the data gathered from 42 sites were 10 out of a possible 15 , and a standard deviation of 2.4 .

From table 3 it is evident that nurses scored poorly with regards to the correct use of protective gear. A significant test performed using the Pearson Chi-square test performed on the data did not show a significant difference between the data from the three districts (CI $=(9.92-$ 10.09), $\mathrm{r}=4.433, \mathrm{df}=2, \mathrm{p}=0.109)$. However when the same test was performed on the three different aspects (i.e. regarding the sharps container, protective gear, and the handling and discarding of body fluids) of the instrument, there was a significant difference on specific items in the three districts. Table 4 highlights the results found from the Chi-Square test.

\section{Patient Satisfaction}

The average score obtained was $13.06(\mathrm{n}=73)$, with 28 being the highest possible score that could be obtained (see table 5). The instrument was developed by the staff of the districts, to reflect their own mission statement. They defined patient satisfaction as the expressed view of inpatients and ambulatory patients of the care they received as compared with the standards set by the Districts.

The Pearson Chi-Square test was performed on the data, the results yielded showed a significant difference between the three districts with regards to the scores obtained from the patient satisfaction questionnaire. (CI $=(1.51-1.80), \mathrm{r}=18.760, \mathrm{df}=4, \mathrm{p}=0.001)$. It would seem that in Amajuba district patient satisfaction is extremely low, with $87 \%$ of patients giving a rating below 10 out of a possible total of 28 .

For individuals that were illiterate, a questionnaire with faces with three different expressions was used. The expressions of the faces indicated, "Satisfied, neither satisfied nor dissatisfied and dissatisfied." The frequencies of the responses are indicated in table 6. A Pearson ChiSquare test performed on this set of data did not show a significant difference between the three districts and the level of patient satisfaction. ( $(\mathrm{CI}=1.37-1.50), \mathrm{r}=5.324$, $\mathrm{df}=4, \mathrm{p}=0.256$ ). 
Table 3: Average of Scores for the three components of the Universal Precautions Checklist

\begin{tabular}{lccc}
\hline ITEM & Ugu $(\mathbf{n}=\mathbf{~ I 5 )}$ & Uthukela (n = I2) & Amajuba (n = I5) \\
\hline Sharps Container & $4.7(95 \%)$ & $3.9(78 \%)$ & $4.3(87 \%)$ \\
Protective Gear & $3.2(46 \%)$ & $3.2(46 \%)$ & $2.5(38 \%)$ \\
Handling and discarding body fluids & $2.7(91 \%)$ & $1.5(53 \%)$ & $2.8(96 \%)$ \\
\hline
\end{tabular}

Table 4: Pearson Chi-Square Results of selected items from the universal precautions checklist

\begin{tabular}{|c|c|c|c|c|}
\hline Item No. & Item & r - value & df & p-value \\
\hline I & Sharps containers/gloves/gowns/masks available in strategic positions & 11.053 & 4 & 0.026 \\
\hline 3 & Sharps containers not overfilled & 6.067 & 2 & 0.048 \\
\hline 8 & Hand washing between patients (also applies to gloved hands) & 12.888 & 6 & 0.045 \\
\hline 12 & $\begin{array}{l}\text { Staff handling soiled linen and medical waste wear protective garments and heavy } \\
\text { duty gloves }\end{array}$ & 35.560 & 4 & 0.000 \\
\hline 14 & Soiled linen put into YELLOW plastic bags-antiseptic added prior to sluicing & 24.052 & 4 & 0.000 \\
\hline 15 & General hygiene maintained e.g. No spillage left unattended & 14.189 & 4 & 0.007 \\
\hline
\end{tabular}

Table 5: Scores of the patient satisfaction questionnaire on long scale

\begin{tabular}{|c|c|c|c|}
\hline SCORE & Ugu $(n=30)$ & Uthukela $(n=20)$ & Amajuba $(n=23)$ \\
\hline $0-10$ & $7(23 \%)$ & $4(20 \%)$ & $20(87 \%)$ \\
\hline $11-20$ & $20(67 \%)$ & $13(65 \%)$ & $3(13 \%)$ \\
\hline OVER 20 & $3(10 \%)$ & $3(15 \%)$ & 0 \\
\hline AVERAGE & 13.5 & 15.25 & 10.6 \\
\hline
\end{tabular}

Table 6: Frequencies of the Patient Satisfaction on short scale

\begin{tabular}{lccc}
\hline Level of Satisfaction & Ugu $(\mathbf{n}=179)$ & Uthukela $(\mathbf{n}=\mathbf{2 2 2})$ & Amajuba $(\mathbf{n}=\mathbf{I 7 8})$ \\
\hline $\begin{array}{lcc}\text { Satisfied } \\
\text { Neither Satisfied nor }\end{array}$ & $120(67 \%)$ & $170(76.6 \%)$ & $128(71.9 \%)$ \\
$\begin{array}{l}\text { Dissatisfied } \\
\text { Dissatisfied }\end{array}$ & $24(13.4 \%)$ & $21(9.5 \%)$ & $22(12.4 \%)$ \\
\hline
\end{tabular}

To investigate the criterion validity of the short faces instrument, the results on this questionnaire was compared with that of the longer one. A Pearson Chi-Square was done and showed a significant difference between the results yielded from these instruments $(\mathrm{r}=23.476, \mathrm{df}=2$, $\mathrm{p}=0.000)$. The difference seems to lie in the Amajuba data, where the "faces" questionnaire gives much the same picture as the other districts, while the long questionnaire gave a very strong negative score.
Nursing Records

A total of 137 records were audited. The average percentage of the records (11\%) with a standard deviation was 2.8 (see table 7), was extremely low.

It is evident from the average of the percentages highlighted above, that the quality of the nursing records in all three districts was generally very poor. A significance of difference test performed on the data using the Pearson Chi-Square test did not show a significant difference 
Table 7: Quality of the Records as a Percentage

\begin{tabular}{lccc}
\hline Quality of the record as $\%$ & Ugu $(\mathrm{n}=\mathbf{4 5})$ & Uthukela $(\mathrm{n}=\mathbf{4 6})$ & Amajuba $(\mathrm{n}=\mathbf{4 6})$ \\
\hline$<10$ & 16 & 21 & 18 \\
$\mathrm{II-20}$ & 29 & 25 & 28 \\
Average & 11 & 11 & 11 \\
\hline
\end{tabular}

Table 8: Scores on the Management of Chronic Illnesses Checklist

\begin{tabular}{|c|c|c|c|}
\hline Score & Ugu $(n=47)$ & Uthukela $(n=48)$ & Amajuba $(n=36)$ \\
\hline $0-5$ & I (2\%) & - & I (2\%) \\
\hline $6-10$ & $22(47 \%)$ & $10(21 \%)$ & 17 (47\%) \\
\hline $11-15$ & $24(51 \%)$ & $38(79 \%)$ & $18(50 \%)$ \\
\hline Average & II & 12 & 10 \\
\hline
\end{tabular}

between the three districts and the quality of the records. $((\mathrm{CI}=10.52-11.46), \mathrm{r}=33.739, \mathrm{df}=26, \mathrm{p}=0.142)$. It was further noted that in one hospital, the district level hospital in the Ugu District, the quality of the records was exceptionally poor. The average percentage obtained of a total of fifteen records that was audited was $9.4 \%$. The quality of the records in the surgical ward was especially poor, here two of the five records that were randomly selected only had one entry (Admission entry), and the patient had been admitted in the unit for three days. In the same unit, one of the records that were randomly selected had no entries, and the patient was admitted for eight days. Four registered nurses (RN's) and 12 nurses from other categories made up the staff of this unit on that day. It housed 59 beds and on that day there was a total of 55 patients. In the Amajuba District there was also a nursing record that had no entries. In this case the unit data showed a very low staff to patient ratio, this unit had only 2 registered nurses (RN's), 3 nurses of other categories, it housed 51 beds and on the day the unit was visited the unit had 51 patients.

\section{Management of Chronic Conditions}

A total of 131 clients were assessed, the highest possible score that could have been obtained was 15 , the average score was 11.16, and the standard deviation was 2.53 . Table 8 highlights the scores that were obtained in the three districts.

From the 131 clients that were assessed, 107 were hypertensive and 32 were diabetics. Of the 107 hypertensive patients, only 30 were controlled (i.e. 23\%) and the remaining 77 were not controlled $(72 \%)$. Of the 32 diabetics, only 12 (38\%) were controlled and the remaining the $20(63 \%)$ was not controlled. The Pearson Chi-
Square test performed on the data showed a significance of difference between the three districts and the scores obtained regarding the quality of care of chronic conditions ((CI 10.72-11.59), $\mathrm{r}=10.845, \mathrm{df}=4, \mathrm{p}=0.028)$. The Uthukela district had a significantly better profile of scores than the other two.

With regards to the compliance to the Essential Drug List (EDL), those clients who were hypertensive, in 35 (27\%) of the cases the medication administered was according to the EDL, and with regards to the diabetics, in $22(17 \%)$ of the cases, the medication administered was according to the EDL.

\section{Discussion}

With regard to both hand-over (58\%) and universal precautions $(67 \%)$ the average scores were much better than some of the components of these scores. In the case of hand-over, one district did particularly poorly, and two aspects of the hand-over (dealing with drugs and with incidents) were very poorly handled. In the case of universal precautions, the use of protective gear is particularly low. This is very disconcerting in the light of the provincial HIV/AIDS prevalence rate of $32.5 \%$ in women attending antenatal clinics [11].

Levels of dissatisfaction amongst patients are high (average $43 \%$ on the long scale and $16 \%$ on the short scale). Even if the Amajuba data were ignored, it would leave about $20 \%$ of patients dissatisfied with the service they received. The average satisfaction score $(72 \%$ on short scale) is similar to that found by Uys [10] in 2000 a study targeting consumers of public psychiatric services in three provinces of the country. No other patient satisfaction studies in South Africa could be found. 
The quality of nursing records is extremely low (11\%). In the article published in 1989 when the NRSS was developed, Uys and Booyens [13] reported an average score of $73 \%$ across government hospitals of different sizes in two provinces of the country. The NRSS is also used in the Free State Province for quality assurance purposes and no score lower than $56 \%$ was found in a recent site visit by the first author to one of these hospitals. Although the nursing resources has deteriorated since the stringent measures introduced in the 1990's, it still seems that another province manages to maintain a higher level of quality in nursing documentation.

The management of chronic illnesses (hypertension and diabetes) had a relatively high average score (73\%) compared to the other scores in this study. However, the crucial items that deal with the actual control of the disease (level of blood pressure and blood sugar) show that the level of control is poor (23\% of patients with hypertension, and $38 \%$ of patients with diabetes). Since the aim of these treatments is to keep the measures in a specific range, these cases have to be seen as maintenance failures. These two illnesses were chosen because there are no historical vertical programmes for these illnesses; such as there are for Tuberculosis, and Sexually Transmitted Illnesses. Their management therefore gives a more valid picture of the care of patients with chronic illnesses receives at $\mathrm{PHC}$ clinics. According to the burden of disease estimates published by the Medical Research Council based on 2000 data, cardio-vascular disease is the second highest cause of death in men and women, and diabetes in tenth on the list for men and 9th for women [9]. The poor level of management at PHC clinics is therefore an important issue for a large portion of the population. This might be related to the lack of compliance with the Essential Drug List. The reasons for the lack of compliance were not explored. Poor availability of drugs or poor knowledge with regard to the Essential Drug List might be reasons for lack of policy implementation of the nurses. This needs further exploration.

There was not much difference between the three health districts, although patient satisfaction was significantly lower in one, and management of chronic illnesses significantly better in another. This means that human resource development programmes can be developed for the whole province. However it should be noted that the significantly higher score of Uthukela on one measure also indicates that a district can do better than average. This might be because the district gives particular attention to that aspect, or it might be an indication of an indication of a better service in the whole of the PHC sector of that district.

\section{Conclusions}

This study has pointed to a number of problems in the quality of care given by nurses in three health districts in South Africa. It has highlighted specific problems in each district and also general problems across all three districts. Some of these problems might be amenable to training and education. However, other management strategies also seem to be indicated. Regular monitoring and feedback to nursing teams, monitoring meetings in the format of perinatal mortality review meetings, and special incentives for higher quality might be considered.

\section{Author Contributions}

LU wrote the research protocol, assisted with the development of the instruments, supervised the research and edited the manuscript. JN did the data collection, the statistical analysis and drafted the manuscript.

\section{Competing interests}

None declared.

\section{Acknowledgements}

Funding for this project was received from the Health Systems Trust.

\section{References}

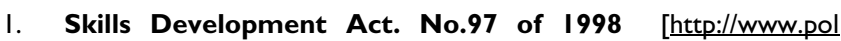
ity.org.za/html/govdocs/legislation/ 1998/act98-097.html]

2. Skills Development Levies Act. No. 9 of 1999 [http://educa tion.pwv.gov.za/Legislation/1999/act9.pdf.pdf]

3. Booysens SW: Introduction to Health Services Management. Cape Town: Juta \& Co. Ltd 1996.

4. Muller M: The Quality of Nursing Service Management in South African Hospitals. Curationis 2000, 23(2):63-69.

5. Conte HR, Plutchik R, Buckley P, Spence DW, Karasu TB: Outpatients view their psychiatric treatment. Hospital and Community Psychiatry 1989, 40(6):641-643.

6. Morris G: Improving quality of services. In Health Systems Trust South African Health Review Durban: Health System Trust; 1999: 175-186.

7. Beattie A, Rispel L, Cabral J: The quality and cost of Primary Health Care in SA. Johannesburg: Centre for Health Policy, University of the Witwatersrand.; 1995.

8. Edwards-Miller J: Measuring quality of care in South African clinics and hospitals. In SA Health Review Durban: Health Systems Trust; 1998:157-193.

9. Bradshaw D, Groenewald P, Laubscher R, Nannan N, Nojilana B, Norman R, Pieterse D, Schneider M: Initial burden of disease estimates for South Africa, 2000. Tygerberg: MRC 2003.

10. Fredriksson J, Berry S: South Africa HIVIAIDS Statistics Retrieved. [http://www.avert.org/safricastats.htm]. October 30, 2003

II. Uys LR, Booyens SW: Standards for nursing documentation in general hospitals in South Africa. Curationis 1989, I 2( I \&2):29-3I.

12. Adler G, Qulo O: HIVIAIDS and STDs. In SA Health Review Durban: Health Systems Trust; 1999:30 I-313.

13. Uys LR: The evaluation of public psychiatric services in three provinces in South Africa. SA Medical Journal 2000, 6:626-628.

\section{Pre-publication history}

The pre-publication history for this paper can be accessed here:

http://www.biomedcentral.com/1472-6955/3/1/prepub 